\title{
Chronic Antipsychotic Treatment Modulates Aromatase (CYP19A1) Expression in the Male Rat Brain
}

\author{
Katarzyna Bogus $^{1} \cdot$ Artur Pałasz $^{1}$ (D) - Aleksandra Suszka-Świtek ${ }^{1} \cdot J^{\text {John J. Worthington }}{ }^{2} \cdot$ Marek Krzystanek $^{3} \cdot$ \\ Ryszard Wiaderkiewicz ${ }^{1}$
}

Received: 12 October 2018 / Accepted: 20 March 2019 / Published online: 9 April 2019

(C) The Author(s) 2019

\begin{abstract}
Antipsychotic drugs, known as the antagonists of dopaminergic receptors, may also affect a large spectrum of other molecular signaling pathways in the brain. Despite the numerous ongoing studies on neurosteroid action and regulation, there are no reports regarding the influence of extended treatment with typical and atypical neuroleptics on brain aromatase (CYP19A1) expression. In the present study, we assessed for the first time aromatase mRNA and protein levels in the brain of rats chronically (28 days) treated with olanzapine, clozapine, and haloperidol using quantitative real-time PCR, end-point RT-PCR, and Western blotting. Both clozapine and haloperidol, but not olanzapine treatment, led to an increase of aromatase mRNA expression in the rat brain. On the other hand, aromatase protein level remained unchanged after drug administration. These results cast a new light on the pharmacology of examined antipsychotics and contribute to a better understanding of the mechanisms responsible for their action. The present report also underlines the complex nature of potential interactions between neuroleptic pharmacological effects and physiology of brain neurosteroid pathways.
\end{abstract}

Keywords Aromatase $\cdot$ Brain $\cdot$ Olanzapine $\cdot$ Clozapine $\cdot$ Neuroleptics

\section{Introduction}

Aromatase (estrogen synthase, CYP19A1), a tissue-specific product of cytochrome P450cyp19a gene located in chromosome 15 , is a key mammalian microsomal enzyme in the process of the conversion of androgens to estrogens (Brocca and Garcia-Segura 2018; Roselli et al. 2009; Stoffel-Wagner 2001). The activation of both appetitive and consummatory sides of male sexual behavior are triggered by testosterone aromatization. A distinct aromatase expression is found in the gonads and several other organs including the brain. In

Artur Pałasz

apalasz@ sum.edu.pl

1 Department of Histology, School of Medicine in Katowice, Medical University of Silesia, ul. Medyków Street 18,

40-752 Katowice, Poland

2 Division of Biomedical and Life Sciences, Faculty of Health and Medicine, Lancaster University, Lancaster LA1 4YQ, UK

3 Department and Clinic Psychiatric Rehabilitation, School of Medicine in Katowice, Medical University of Silesia, ul. Ziolowa 45/ 47, 40-635 Katowice, Poland rats, the presence of aromatase has been detected exclusively in the brain, testes, and ovaries (Kato et al. 1997). Expression of aromatase is generally limited to adult neurons (GarciaSegura et al. 2003), it does not normally occur in the glial cells except in reactive astrocytes (Pedersen and Saldanha 2017, Azcoitia et al. 2003; Garcia-Segura et al. 1999) and radial glia (Xing et al. 2016) following neurotoxic and mechanical injury. Aromatase activity is modulated by steroidrelated transcriptional changes but also more rapidly by phosphorylation cascades. Sexual activity of both male and female rodents may also affect brain aromatase activity, probably through glutamatergic signaling (Balthazart 2017; de Bournonville et al. 2017; Antaramian et al. 2015). Recent evidence suggests a role for brain aromatase in the development of serotoninergic pathways in lower vertebrates (Ulhaq and Kishida 2018). Since the function of steroid sex hormones is relatively well studied at the level of the reproductive glands, their physiological roles in brain structures are still insufficiently explained. In the various regions of the human brain, such as the frontal and temporal lobes, hippocampal formation, and hypothalamus, a distinct, sex-independent aromatase mRNA expression has been detected (Stoffel-Wagner 2001). Interestingly, some of these structures show a diverse 
pattern of estrogen receptor isoform expression, e.g., in the hypothalamic nuclei ER $\alpha$ predominates, whereas in the hippocampal and cortical areas, ER $\beta$ is most abundant (Simpson et al. 2002). Hippocampal aromatase seems to be necessary to induce long-term potentiation (LTP) and maintain neural plasticity (Azcoitia et al. 2017, Vierk et al. 2012). On the other hand, a recent study revealed a sex-dependent involvement of aromatase in the regulation of synaptic functions in the rat basolateral amygdala, a main center of fear responses, where the neurosteroid $17 \beta$-estradiol (E2) is synthesized. It may be important for the understanding of sex differences in the course of some neuropsychiatric diseases, e.g., bipolar disorder or anxiety (Bender et al. 2017). Moreover, there are suggestions that the neuropsychiatric manifestations of brain aromatase blockade, e.g., during post-menopausal pharmacotherapy and subsequent inhibition of central estrogen synthesis, could be further associated with modulations of monoaminergic pathways in the prefrontal cortex and hippocampus, the core structures involved in mood learning and memory processes (Kokras et al. 2017; Aydin et al. 2008).

Brain-derived steroids, also known as neurosteroids, may be synthesized by both neurons and glial cells (Benarroch 2007). Numerous reports show that they act as neurotransmitter-like factors as they are released at precise places within neural populations and can regulate very quickly both cognitive and behavioral functions (Balthazart and Ball 2006; Dewing et al. 2007; Saldanha et al. 2011; Remage-Healey 2014). Neurosteroids regulate NMDA and $\mathrm{GABA}_{\mathrm{A}}$ receptor functions acting as potent allosteric modulators of the ionic channel molecules (Saldanha et al. 2009; Benarroch 2007). They also affect opioid sigma receptors. Interestingly, changes in neurosteroid signaling may contribute to the pathogenesis of anxiety and depression; furthermore, selective serotonin reuptake inhibitors (SSRI) may act at least in part via the restoration of neurosteroid function (Longone et al. 2011). A potential role of brain neurosteroids in the pathogenesis of schizophrenia is also postulated (Shulman and Tibbo 2005). Several medications known as the aromatase inhibitors, such as aromasin, anastrozole, or letrozole, can block estrogen synthesis through the direct suppression of their conversion to androgens (Czajka-Oraniec and Simpson 2010). Noteworthy, both estrogens and their precursors seem to have neuroprotective properties (Saldanha et al. 2009; Stoffel-Wagner 2001).

Olanzapine, an atypical neuroleptic, has an affinity to various brain receptors including dopaminergic $\mathrm{D}_{1}-\mathrm{D}_{5}$, serotoninergic $5-\mathrm{HT}_{2 \mathrm{~A} / 2 \mathrm{C}}, 5-\mathrm{HT}_{3}, 5-\mathrm{HT}_{6}, \alpha_{1}$-adrenergic, muscarinic $\mathrm{M}_{1}-\mathrm{M}_{5}$, and histaminergic $\mathrm{H}_{1}$. This antipsychotic drug reduces positive schizophrenia symptoms through a decrease of dopaminergic neuron activity, mainly in the mesolimbic tract, but it exerts only a minor effect on the striatal motor systems (Harvey et al. 2016; Leucht et al. 2013). The metabolism of olanzapine occurs in the liver where two cytochrome P450 isoforms CYP1A2 and CYP2D6 proceed drug biotransformation into N-desmethylolanzapine and 2-hydroxyolanzapine respectively (Prior and Baker 2003). The final, inactive, olanzapine metabolite 10-N-glucuronide does not cross the blood-brain barrier (Aravagiri et al. 1999).

Clozapine, another dibenzodiazepine-derived atypical neuroleptic with high inhibitory affinity toward dopaminergic D4 receptors, is a less potent dopamine D2 blocker than typical antipsychotics. Clozapine may also inhibit glutamate reuptake, through a decreased expression of both neuronal and astrocytic glycine transporters: EAAT3 and EAAT2 respectively (Krzystanek et al. 2015). It may also inhibit the neuronal D-aspartate oxidase (DDO) activity that increases glutamate release in the mouse brain (Sacchi et al. 2017). The two main products of clozapine biotransformation via liver microsomal isoforms CYP1A2 and CYP3A4 are desmethylclozapine (norclozapine) and N-oxide clozapine (Spina et al. 2003; Linnet and Olesen 2000; Eiermann et al. 1997).

Haloperidol, a typical but still commonly administered $\mathrm{D}_{2}$ receptor antagonist, effectively reduces psychosis suggesting impaired dopaminergic signaling is a key mechanism of positive schizophrenia symptoms (Gass et al. 2013). However, it shows a wide spectrum of unfavorable side effects including akathisia, tardive dyskinesia, neuroleptic malignant syndrome, and heart rhythm disturbances (Leucht et al. 2013; Stracina et al. 2015). Noteworthy, haloperidol is a non-specific neuroleptic with affinity to numerous receptors, including dopamine D2, serotonin 5 HT2, $\alpha$-adrenergic, and $\sigma$-opioid receptors (Cobos et al. 2007; Roth et al. 1998). Haloperidol undergoes biotransformation, mainly oxidative dealkylation by CYP3A4 and CYP2D6 isoforms. An increase of the serum concentration of coadministered drugs, known as the substrates for CYP2D6, was reported suggesting a role of haloperidol metabolites in enzyme inhibition (Shin et al. 2001). Interestingly, brain CYP2Ds may alter some side effects of haloperidol and other neuroleptics metabolized by these isoforms (Miksys et al. 2017).

A number of findings revealed that aromatase expression as well as neurosteroid synthesis may be significantly modulated by various neuropsychiatric medications including antidepressants and benzodiazepines (Chen et al. 2016; Schüle et al. 2011; Longone et al. 2011; Niwa et al. 2008, Pinna et al. 2006). However, very little is known about effects of neuroleptic administration on the aforementioned processes. The aim of the study was to comparatively determine, for the first time, whether long-term treatment with both atypical (olanzapine, clozapine) and typical (haloperidol) antipsychotic drugs affects aromatase expression in the rat brain.

\section{Materials and Methods}

Adult (5 months old, 210-240 g) male Sprague-Dawley rats from the Medical University of Silesia Experimental Centre were housed at $22{ }^{\circ} \mathrm{C}$ with a regular 12/12 light-darkness cycle with access to standard Murigran chow and water ad libitum. 
All experimental procedures were approved by the Local Bioethical Committee at the Medical University of Silesia (agreement no. 36/2012) and were conducted in a manner consistent with NIH Guidelines for Care and Use of Laboratory Animals. Four groups of animals $(n=5)$ had received respectively control vehicle, olanzapine $(10 \mathrm{mg} / \mathrm{kg} /$ day), clozapine $(20 \mathrm{mg} / \mathrm{kg} / \mathrm{day})$, and haloperidol $(1 \mathrm{mg} / \mathrm{kg} /$ day), by intraperitoneal injection for 28 days. Three hours after the last drug administration, rats were quickly anesthetized with isoflurane and sacrificed. Their brains were removed and then prepared for further molecular procedures.

Brain hemispheres were homogenized immediately after isolation using an ultrasound homogenizer (Heildolph DIAX 900, Germany). Total mRNA was extracted via phenolchloroform method using Trizol ${ }^{\mathrm{TM}}$ as previously described. Collected mRNA samples were transcribed into cDNA during incubation in a buffered solution of reverse transcriptase MMLV-RT with RNAsin, oligo-dT, and a mix of nucleotides at $42{ }^{\circ} \mathrm{C}$ for 60 min using DNA Thermal Cycler 480 (Perkin Elmer Inc., Waltham, MA) After that, quantitative real-time PCR reaction (qPCR) was performed by FastStart SYBR Green Master mix (Roche) in a Light Cycler 196 (Roche). Thermal cycler 32 rounds: $1 \mathrm{~min}$ at $94{ }^{\circ} \mathrm{C}, 1 \mathrm{~min}$ at $62^{\circ} \mathrm{C}$, and finally $90 \mathrm{~s}$ at $72^{\circ} \mathrm{C}$. Beta-2-microglobulin (B2m) was chosen as a standard internal housekeeping reference gene. cDNA was amplified using the following primers (Sigma, Life Science): aromatase CYP19A1 (126 bp): Forward: 5'TAAAAGATGGCACACAAAGAGTGC, Reverse: 5'ACCGAGGTTACCTGGATCTGC; B2m: F: 5'-CGAG ACCGATGTATATGCTTGC, R: GTCCAGATGATTCA GAGCTCCA. All qPCR data were analyzed using the comparative $\mathrm{Cq}$ method. Finally, the formula $2^{-\Delta \Delta \mathrm{Cq}}$ was used to achieve relative quantitation of mRNA expression. Additionally, the end-point RT-PCR method was also used to confirm aromatase mRNA expression. The PCR reaction was performed in a Peltier Thermal Cycler PT-200 (MJ Research Inc., Watertown, MA) with the same CYP19A1 primer for 32 rounds: $1 \mathrm{~min}$ at $94{ }^{\circ} \mathrm{C}, 1 \mathrm{~min}$ at $65^{\circ} \mathrm{C}$, and finally 90 s at $72{ }^{\circ} \mathrm{C}$. Glyceraldehyde phosphate dehydrogenase was an internal housekeeping reference gene: GAPDH: Forward: 5'-GTGAACGGATTTGGCCGTATCG', Reverse: 5'-ATCACGCCACAG CTTTCCAGAGG-3. Products of PCR amplification were separated on a $2 \%$ agarose gel, visualized with ethidium bromide, and photographed in a UV light chamber. Semi-quantitative densitometric analysis was performed with the use of OneDScan software (Scanalytics). The results were expressed as relative (vs. GAPDH) integrated optical density (IOD) showing relative gene expression.

The second half of brain hemispheres were homogenized (Potter-Elvehjem system) in $0.25 \mathrm{M}$ sucrose in Tris/ $\mathrm{HCl}$ ( $\mathrm{pH}$ 7.4). The homogenate was centrifuged at $10,000 \times \mathrm{g}$ for $20 \mathrm{~min}$ and then supernatant was centrifuged again at $105,000 \times g$ for $1 \mathrm{~h}$ to sediment the microsomal fraction that was suspended in $20 \%$ glycerol in phosphate buffer. Microsomal proteins were separated using SDS/ polyacrylamide gel electrophoresis (Biorad) and transferred onto nitrocellulose membrane (Millipore). Aromatase was detected with rabbit anti-rat aromatase polyclonal primary antibody (Abcam, AB18995). The secondary antibody was goat anti-rabbit IgG conjugated with alkaline phosphatase. BCIP/ Nitrotetrazolium Blue was used to visualize the enzyme activity. Immunoblots were quantified using One-D-Scan Gel Analysis program (Scanalytics). The results were expressed as integrated optical density (IOD) showing the relative protein expression.

Statistical analysis was performed using Statistica 10 (Systat software). Gaussian distribution and variance homogeneity were estimated with Shapiro-Wilk and Levene's tests. The results were then statistically analyzed using one-way ANOVA and HSD Tukey's tests. Differences were considered statistically significant at $p<0.05$.

\section{Results}

The present real-time PCR study shows that whole brain aromatase mRNA expression was significantly increased after long-term treatment with clozapine $(33.94 \pm 4.15)$ and haloperidol administration $(22.57 \pm 2.89)$ vs. control: $(0.96 \pm 0.56$; $p=0.0002$, Figs. 1 and 2). Moreover a distinct correlation was observed between the effects of clozapine and haloperidol $(p=0.0018)$. Surprisingly, olanzapine did not affect the

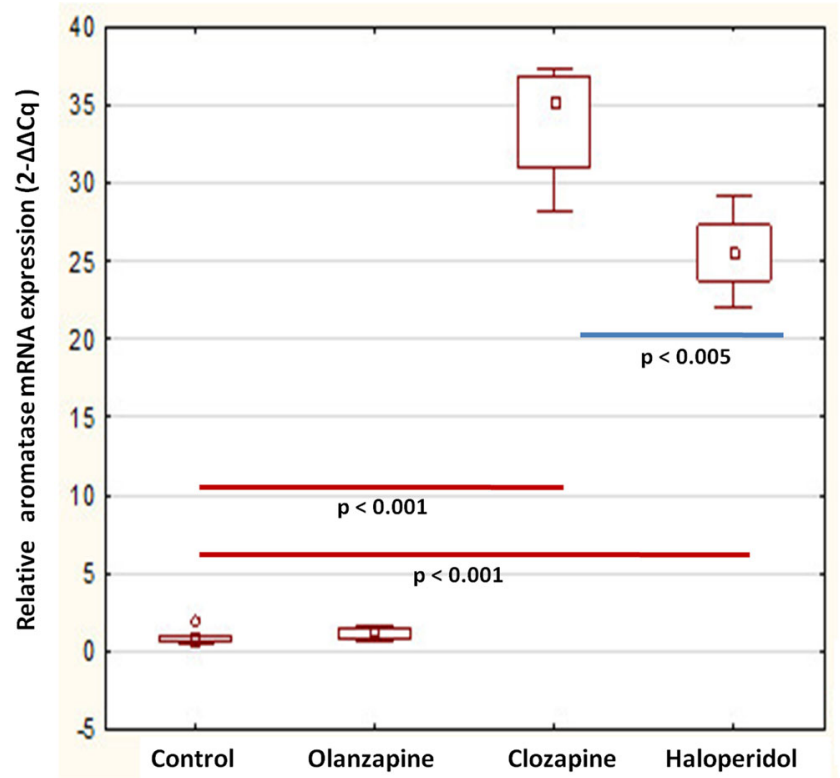

Fig. 1 Quantitative real-time PCR results of relative aromatase mRNA expression levels in the rat brain. Obtained results were normalized to GAPDH housekeeping reference gene. Data are presented as mean $2^{-\Delta \Delta \mathrm{Cq}}$. One-way ANOVA followed by Tukey's HSD post-hoc test was used for statistical analysis (experimental group vs control). $p \leq$ 0.05 is considered as statistically significant 
aromatase mRNA level $(1.18 \pm 0.43$ vs. control: $0.961 \pm 0.56$; $p=0.99)$. The aromatase protein levels measured using Western blotting method were in turn not significantly changed after treatment with all studied antipsychotic drugs (olanzapine: $0.83 \pm 0.24$; clozapine: $0.70 \pm 0.18$ haloperidol: $0.67 \pm 0.15$ vs. control $0.62 \pm 0.15, p>0.05$, Fig. 3 ).

\section{Discussion}

Although aromatase (CYP19A1) does not take part in the central metabolism of antipsychotic drugs in a direct manner, being a crucial player in the steroidogenesis it may distinctly modify their pharmacological effects in the brain, e.g., by alterations of local $\mathrm{Ca}^{2+}$ levels and ionic channels permeability in some neuronal populations. At present, accumulating investigations focus on brain neurosteroid physiology; however, there are no reports dealing with changes in rat brain aromatase expression related to neuroleptic action. Studies on the effects of antipsychotic drugs on central neurosteroid signaling could potentially enlighten mechanistic pathways explaining some of their alternative pharmacological activity.

An observed increase of aromatase mRNA expression after long-term clozapine administration may correspond only partially and indirectly with the previous studies reporting an acute elevation of brain $3 \alpha, 5 \alpha$-tetrahydroprogesterone ( $3 \alpha, 5 \alpha$-THP),

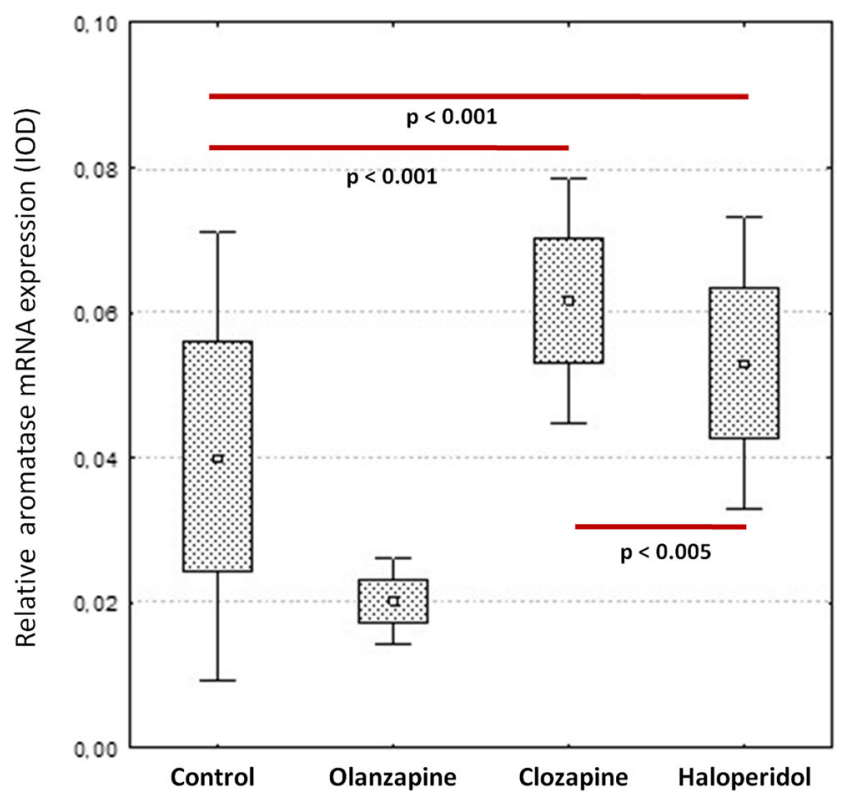

Fig. 2 Semi-quantitative RT-PCR results of relative aromatase mRNA expression levels in the rat brain. Obtained results were normalized to GAPDH housekeeping reference gene. Data are presented as mean integrated optical density (IOD). One-way ANOVA followed by Tukey's HSD post-hoc test was used for statistical analysis (experimental group vs control). $p \leq 0.05$ is considered as statistically significant

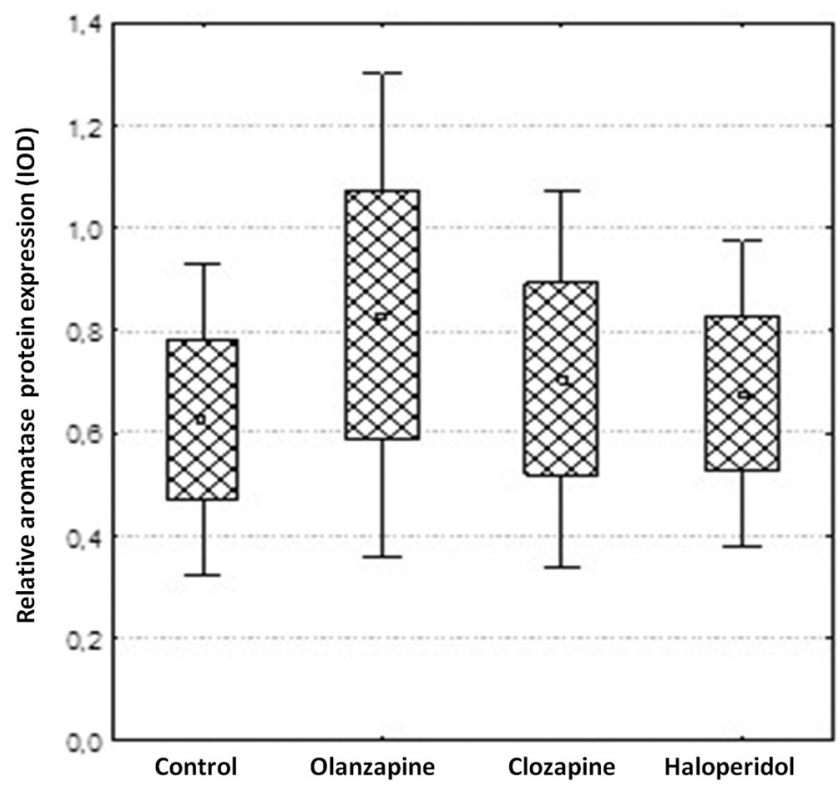

Fig. 3 Relative aromatase protein levels in the rat brain. Data are presented as mean integrated optical density (IOD). One-way ANOVA followed by Tukey's HSD post-hoc test was used for statistical analysis (experimental group vs control). $p \leq 0.05$ is considered as statistically significant

allopregnanolone, and allotetrahydrodeoxycorticosterone (THDOC) levels in rats acutely treated with clozapine and olanzapine (Barbaccia et al. 2001; Marx et al. 2006). On the other hand, extended administration of clozapine in drug-resistant schizophrenic patients did not affect circulating levels of the $3 \alpha, 5 \alpha$-THP and THDOC (Monteleone et al. 2004). In our study, surprisingly, no changes in aromatase mRNA level after treatment with olanzapine occurred, contradicting previous studies (Barbaccia et al. 2001; Marx et al. 2006). The mechanism of clozapine action at the level of aromatase-expressing neurons is not clear. Several possibilities can be considered to explain how this antipsychotic modulates neuronal aromatase production (Fig. 4). Hypothetically, an increase in aromatase mRNA expression may be caused by blockade of selective dopamine receptors located in certain neuronal populations. However, pharmacological study, by Xing et al. 2016, on cultured stem-like radial glial cells (RGCs) showed a cAMP-dependent upregulation of aromatase B mRNA expression after D1 receptor activation by the selective agonist (flupentixol). Moreover, in vitro studies showed that brain aromatase activity was inhibited by both D1/D2 agonists (apomorphine, RU-24213) and antagonists (sulpiride, spiperone, pimozide) (Absil et al. 2001), suggesting that the observed effects are not mediated through binding to dopamine receptors. Because the presence of glutamate AMPA/kainate and NMDA receptors in the aromatase-expressing cells has been confirmed (Balthazart et al. 2003), a glutamatergic hypothesis of clozapine action may also be suggested. Clozapine may enhance neurotransmitter action by increasing its synaptic concentration 


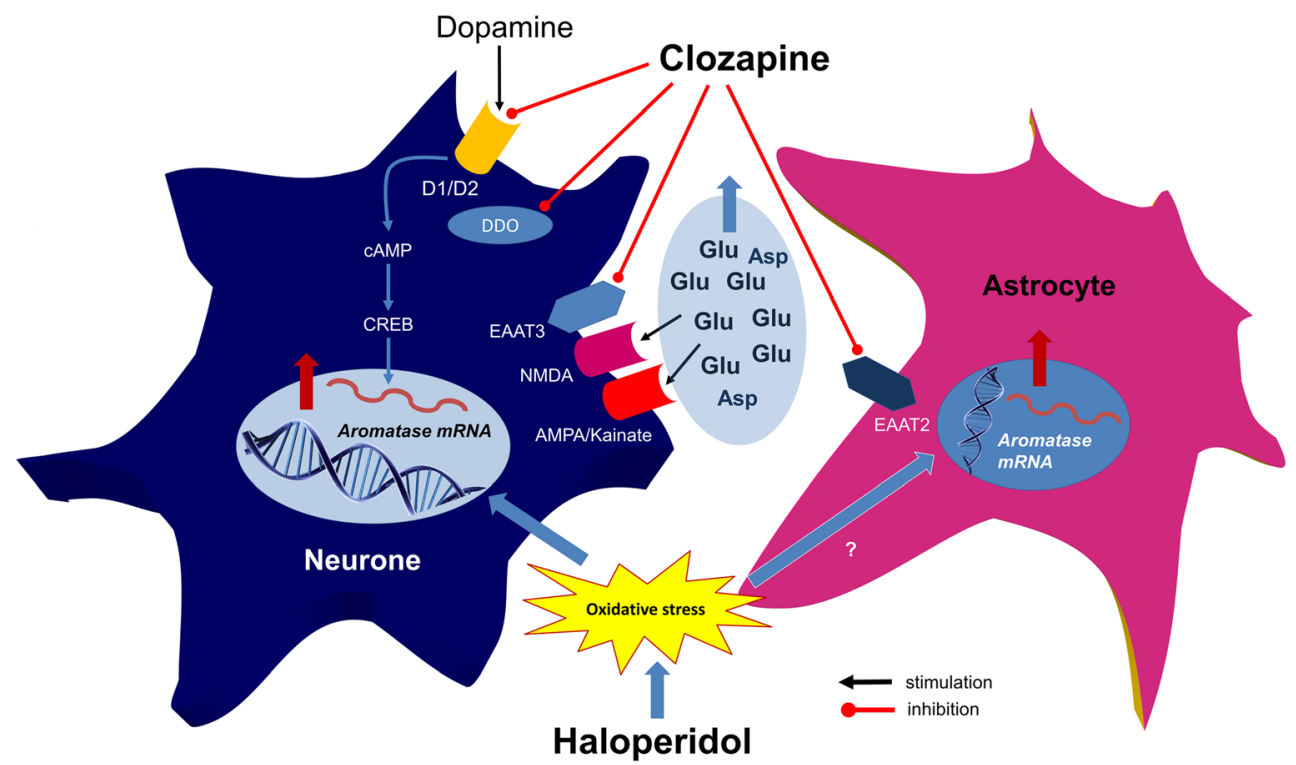

Fig. 4 A hypothetical mechanism of the effect of olanzapine and haloperidol on aromatase expression in the rat brain. The CYP19A1 expression in some neurons can probably be modulated by their glutamate NMDA and AMPA/kainate receptors. Clozapine may increase glutamate/aspartate concentration through the inhibition of excitatory amine acids transporters 2 and 3 (EAAT2/EAAT3) and D-aspartate oxidase (DDO) in neurons and astrocytes. Haloperidol-related oxidative stress may in turn stimulate both neuronal and glial aromatase expression that can possibly be a kind of protective mechanisms against drug toxicity. NMDA, N-methyl-D-aspartate glutamate receptor; AMPA, $\alpha$-amino3-hydroxy-5-methyl-4-isoxazolepropionic acid glutamate receptor; D1,D2 dopamine receptors; cAMP, cyclic AMP, CREB, cAMP response element binding protein via aforementioned EAATs' or DDO blockage (Krzystanek et al. 2015; Sacchi et al. 2017), rather than through binding to glutamate receptors (Barygin et al. 2017). Nevertheless, pharmacological stimulation with glutamate agonists caused an elevation in neuronal calcium levels that quickly depresses the aromatase activity in rodent hypothalamic explants (Balthazart et al. 2006), which is conflicting to the mechanism proposed above. There are also reports that hippocampal aromatase activity and local synthesis of estradiol or pregnenolone may be stimulated by NMDA-dependent calcium influx into the neuroplasm (Hojo et al. 2004; Shibuya et al. 2003). Neurosteroids may therefore act as paracrine modulators of the neural transmission, thereby regulating memory processing in the hippocampus.

Neuronal aromatase activity may play an important role in the putative neuroprotective action of estrogens. An increase of aromatase activity was reported in the rat hippocampus, striatum, and cortex after both toxic and mechanical brain injury (Saldanha et al. 2009). In the present study, long-term treatment with haloperidol increased CYP19A1 mRNA expression in whole brain homogenates. Haloperidol has numerous neurotoxic properties (Nasrallah and Chen 2017; Isom et al. 2013), e.g., inducing disturbances in the oxidativeantioxidative balance (Raudenska et al. 2013). Long-term treatment with haloperidol distinctly modulated the activity of antioxidant enzymes in the rat brain, which correlated with the level of lipid peroxidation (Pillai et al. 2007). An extended haloperidol administration disturbed glutamatergic transmission in the rat prefrontal cortex, that was mainly an effect of NMDAR activity inhibition caused by decreased NR1 and NR2A but not NR2B subunit expression (Fumagalli et al. 2008; Leveque et al. 2000). Possibly, the elevation of aromatase mRNA expression observed in our study may be part of a neuronal protective mechanism against an extended treatment with this drug (Fig. 4). An increase of aromatase mRNA level was not reflected in alterations of protein expression in whole brain homogenates. We cannot therefore precisely estimate to what extent the changes observed affected the potential local synthesis of neuroactive estrogens. The particular brain regions and neuronal assemblies may probably represent different patterns of CYP19A1 protein synthesis after neuroleptic pharmacomodulation. To sum up, antipsychotics may affect aromatase expression in the rat brain, which may be one of the alternative ways of their action in the CNS. A regulatory impact on brain steroidogenesis may be one of the clinically important, so far unknown, possibly sex-dependent mechanisms of pharmacological effects triggered by both typical and atypical neuroleptics.

It should be pointed out that there are some limitations to our study. For instance, the mRNA and protein levels in the precisely defined brain structures instead of the whole 
hemispheres were not measured, and the estrogen concentrations were not determined and the precise analysis of signaling pathways was not provided.

Nevertheless, this new finding represents an initial introduction to forthcoming experimental works on the relationships between neuroleptic action and brain steroidogenesis in animal model. Undoubtedly, these initial data require further basic pharmacological, biochemical, and behavioral studies on the wider spectrum of antipsychotic drugs.

Compliance with Ethical Standards All experimental procedures were approved by the Local Bioethical Committee at the Medical University of Silesia (agreement no. 36/2012) and were conducted in a manner consistent with NIH Guidelines for Care and Use of Laboratory Animals.

Open Access This article is distributed under the terms of the Creative Commons Attribution 4.0 International License (http:// creativecommons.org/licenses/by/4.0/), which permits unrestricted use, distribution, and reproduction in any medium, provided you give appropriate credit to the original author(s) and the source, provide a link to the Creative Commons license, and indicate if changes were made.

\section{References}

Absil P, Baillien M, Ball GF, Panzica GC, Balthazart J (2001) The control of preoptic aromatase activity by afferent inputs in Japanese quail. Brain Res Brain Res Rev 37:38-58

Antaramian A, González-Gallardo A, García-Ugalde C, Portillo W, Paredes RG (2015) Steroid receptors and aromatase gene expression in different brain areas of copulating and sexually sluggish male rats. J Sex Med 12:2267-2275

Aravagiri M, Teper Y, Marder SR (1999) Pharmacokinetics and tissue distribution of olanzapine in rats. Biopharm Drug Dispos 20:369377

Aydin M, Yilmaz B, Alcin E, Nedzvetsky VS, Sahin Z, Tuzcu M (2008) Effects of letrozole on hippocampal and cortical catecholaminergic neurotransmitter levels, neural cell adhesion molecule expression and spatial learning and memory in female rats. Neuroscience 151: 186-194

Azcoitia I, Sierra A, Veiga S, Garcia-Segura LM (2003) Aromatase expression by reactive astroglia is neuroprotective. Ann N Y Acad Sci 1007:298-305

Azcoitia I, Arevalo MA, Garcia-Segura LM (2017) Neural-derived estradiol regulates brain plasticity. J Chem Neuroanat 89:53-59

Balthazart J (2017) Steroid metabolism in the brain: from bird watching to molecular biology, a personal journey. Horm Behav 93:137-150

Balthazart J, Ball GF (2006) Is brain estradiol a hormone or a neurotransmitter? Trends Neurosci 29:241-249

Balthazart J, Baillien M, Charlier TD, Cornil CA, Ball GF (2003) Multiple mechanisms control brain aromatase activity at the genomic and non-genomic level. J Steroid Biochem Mol Biol 86:367379

Balthazart J, Baillien M, Ball GF (2006) Rapid control of brain aromatase activity by glutamatergic inputs. Endocrinology 147:359-366

Barbaccia ML, Affricano D, Purdy RH, Maciocco E, Spiga F, Biggio G (2001) Clozapine, but not haloperidol, increases brain concentrations of neuroactive steroids in the rat. Neuropsychopharmacology 25:489-497
Barygin OI, Nagaeva EI, Tikhonov DB, Belinskaya DA, Vanchakova NP, Shestakova NN $(2017,1660)$ Inhibition of the NMDA and AMPA receptor channels by antidepressants and antipsychotics. Brain Res: $58-66$

Benarroch EE (2007) Neurosteroids- endogenous modulators of neuronal excitability and plasticity. Clinical implications of neuroscience research. Neurology 68:945-948

Bender RA, Zhou L, Vierk R, Brandt N, Keller A, Gee CE, Schäfer MK, Rune GM (2017) Sex-dependent regulation of aromatase-mediated synaptic plasticity in the basolateral amygdala. J Neurosci 37:15321545

Brocca ME, Garcia-Segura LM (2018) Non-reproductive functions of aromatase in the central nervous system under physiological and pathological conditions. Cell Mol Neurobiol. https://doi.org/10. 1007/s10571-018-0607-4

Chen SL, Zang Y, Zheng WH, Wei XH, Liu XG (2016) Inhibition of neuropathic pain by a single intraperitoneal injection of diazepam in the rat: possible role of neurosteroids. Chin J Physiol 59:9-20

Cobos EJ, Del Pozo E, Baeyens JM (2007) Irreversible blockade of sigma-1 receptors by haloperidol and its metabolites in Guinea pig brain and SH-SY5Y human neuroblastoma cells. J Neurochem 102: $812-825$

Czajka-Oraniec I, Simpson ER (2010) Aromatase research and its clinical significance. Pol J Endocrinol 61:126-134

de Bournonville C, Ball GF, Balthazart J, Cornil CA (2017) Rapid changes in brain aromatase activity in the female quail brain following expression of sexual behaviour. J Neuroendocrinol 29(11). https:// doi.org/10.1111/jne.12542

Dewing P, Boulware MI, Sinchak K, Christensen A, Mermelstein PG, Micevych P (2007) Membrane estrogen receptor-Â interactions with metabotropic glutamate receptor 1a modulate female sexual receptivity in rats. J Neurosci 27:9294-9300

Eiermann B, Engel G, Johansson I, Zanger UM, Bertilsson L (1997) The involvement of CYP1A2 and CYP3A4 in the metabolism of clozapine. Br J Clin Pharmacol 44:439-446

Fumagalli F, Frasca A, Racagni G, Riva MA (2008) Dynamic regulation of glutamatergic postsynapitic activity in rat prefrontal cortex by repeated administration of antipsychotic drugs. Mol Pharmacol 73: $1484-1490$

Garcia-Segura LM, Naftolin F, Hutchison JB, Azcoitia I, Chowen JA (1999) Role of astroglia in estrogen regulation of synaptic plasticity and brain repair. J Neurobiol 40:574-584

Garcia-Segura LM, Veiga S, Sierra A, Melcangi RC, Azcoitia I (2003) Aromatase: a neuroprotective enzyme. Prog Neurobiol 71:31-41

Gass N, Schwarz AJ, Sartorius A, Cleppien D, Zheng L, Schenker E, Risterucci C, Meyer-Lindenberg A, Weber-Fahr W (2013) Haloperidol modulates midbrain-prefrontal functional connectivity in the rat brain. Eur Neuropsychopharmacol 10:1310-1319

Harvey RC, James AC, Shields GE (2016) A systematic review and network meta-analysis to assess the relative efficacy of antipsychotics for the treatment of positive and negative symptoms in early-onset schizophrenia. CNS Drugs 30:27-39

Hojo Y, Hattori TA, Enami T, Furukawa A, Suzuki K, Ishii HT, Mukai H, Morrison JH, Janssen WG, Kominami S, Harada N, Kimoto T, Kawato S (2004) Adult male rat hippocampus synthesizes estradiol from pregnenolone by cytochromes P45017alpha and P450 aromatase localized in neurons. Proc Natl Acad Sci U S A 101:865-870

Isom AM, Gudelsky GA, Benoit SC, Richtand NM (2013) Antipsychotic medications, glutamate, and cell death: a hidden, but common medication side effect? Med Hypotheses 80:252-258

Kato J, Yamada- Mouri N, Hirata S (1997) Structure of aromatase mRNA in the rat brain. J Steroid Biochem Mol Biol 61:381-385

Kokras N, Pastromas N, Papasava D, de Bournonville C, Cornil CA, Dalla C (2017) Sex differences in behavioral and neurochemical effects of gonadectomy and aromatase inhibition in rats. Psychoneuroendocrinology 87:93-107 
Krzystanek M, Bogus K, Pałasz A, Krzystanek E, Worthington JJ, Wiaderkiewicz R (2015) Effects of long-term treatment with the neuroleptics haloperidol, clozapine and olanzapine on immunoexpression of NMDA receptor subunits NR1, NR2A and NR2B in the rat hippocampus. Pharmacol Rep 67:965-969

Leucht S, Cipriani A, Spineli L, Mavridis D, Orey D, Richter F, Samara M, Barbui C, Engel RR, Geddes JR, Kissling W, Stapf MP, Lässig B, Salanti G, Davis JM (2013) Comparative efficacy and tolerability of 15 antipsychotic drugs in schizophrenia: a multiple-treatments meta-analysis. Lancet 382:951-962

Leveque JC, Macías W, Rajadhyaksha A, Carlson RR, Barczak A, Kang S, Li XM, Coyle JT, Huganir RL, Heckers S, Konradi C (2000) Intracellular modulation of NMDA receptor function by antipsychotic drugs. J Neurosci 20:4011-4020

Linnet K, Olesen OV (2000) Metabolism of clozapine by cDNAexpressed human cytochrome P450 enzymes. Drug MetaboDispos 25:1379-1383

Longone P, di Michele F, D'Agati E, Romeo E, Pasini A, Rupprecht R (2011) Neurosteroids as neuromodulators in the treatment of anxiety disorders. Front Endocrinol (Lausanne) 2:55

Marx CE, Shampine LJ, Duncan GE, VanDoren MJ, Grobin AC, Massing MW, Madison RD, Bradford DW, Butterfield MI, Lieberman JA, Morrow AL (2006) Clozapine markedly elevates pregnenolone in rat hippocampus, cerebral cortex, and serum: candidate mechanism for superior efficacy? Pharmacol Biochem Behav 84:598-608

Miksys S, Wadji FB, Tolledo EC, Remington G, Nobrega JN, Tyndale RF (2017) Rat brain CYP2D enzymatic metabolism alters acute and chronic haloperidol side-effects by different mechanisms. Prog Neuro-Psychopharmacol Biol Psychiatry 78:140-148

Monteleone P, Fabrazzo M, Serra M, Tortorella A, Pisu MG, Biggio G, Maj M (2004) Long-term treatment with clozapine does not affect morning circulating levels of allopregnanolone and THDOC in patients with schizophrenia: a preliminary study. J Clin Psychopharmacol 24(4):437-440

Nasrallah HA, Chen AT (2017) Multiple neurotoxic effects of haloperidol resulting in neuronal death. Ann Clin Psychiatry 29:195-202

Niwa T, Okada K, Hiroi T, Imaoka S, Narimatsu S, Funae Y (2008) Effect of psychotropic drugs on the 21-hydroxylation of neurosteroids, progesterone and allopregnanolone, catalyzed by rat CYP2D4 and human CYP2D6 in the brain. Biol Pharm Bull 31:348-351

Pedersen AL, Saldanha CJ (2017) Reciprocal interactions between prostaglandin E2- and estradiol-dependent signaling pathways in the injured zebra finch brain. J Neuroinflammation 14:262

Pillai A, Parikh V, Terry AV Jr, Mahadik SP (2007) Long-term antipsychotic treatments and crossover studies in rats: differential effects of typical and atypical agents on the expression of antioxidant enzymes and membrane lipid peroxidation in rat brain. J Psychiatr Res 41: 372-386

Prior TI, Baker GB (2003) Interactions between the cytochrome P450 system and the second-generation antipsychotics. J Psychiatry Neurosci 28:99-112

Raudenska M, Gumulec J, Babula P, Stracina T, Sztalmachova M, Polanska H, Adam V, Kizek R, Novakova M, Masarik M (2013) Haloperidol cytotoxicity and its relation to oxidative stress. Mini Rev Med Chem 14:1993-1998

Remage-Healey L (2014) Frank Beach award winner: steroids as neuromodulators of brain circuits and behavior. Horm Behav 66: $552-560$
Roselli CE, Liu M, Hurn PD (2009) Brain aromatization: classic roles and new perspectives. Semin Reprod Med 27:207-217

Roth BL, Meltzer HY, Khan N (1998) Binding of typical and atypical antipsychotic drugs to multiple neurotransmitter receptors. Adv Pharmacol 42:482-485

Pinna G, Costa E, Guidotti A (2006) Fluoxetine and norfluoxetine stereospecifically and selectively increase brain neurosteroid content at doses that are inactive on 5-HT reuptake. Psychopharmacology 186: 362-372

Sacchi S, Novellis V, Paolone G, Nuzzo T, Iannotta M, Belardo C, Squillace M, Bolognesi P, Rosini E, Motta Z, Frassineti M, Bertolino A, Pollegioni L, Morari M, Maione S, Errico F, Usiello A (2017) Olanzapine, but not clozapine, increases glutamate release in the prefrontal cortex of freely moving mice by inhibiting Daspartate oxidase activity. Sci Rep 7:46288

Saldanha CJ, Duncan KA, Walters BJ (2009) Neuroprotective actions of brain aromatase. Front Neuroendocrinol 30:106-118

Saldanha CJ, Remage-Healey L, Schlinger BA (2011) Synaptocrine signaling: steroid synthesis and action at the synapse. Endocr Rev 32: 532-549

Schüle C, Eser D, Baghai TC, Nothdurfter C, Kessler JS, Rupprecht R (2011) Neuroactive steroids in affective disorders: target for novel antidepressant or anxiolytic drugs? Neuroscience 191:55-77

Shibuya K, Takata N, Hojo Y, Furukawa A, Yasumatsu N, Kimoto T, Enami T, Suzuki K, Tanabe N, Ishii H, Mukai H, Takahashi T, Hattori TA, Kawato S (2003) Hippocampal cytochrome P450s synthesize brain neurosteroids which are paracrine neuromodulators of synaptic signal transduction. Biochim Biophys Acta 1619:301-316

Shin JG, Kane K, Flockhart DA (2001) Potent inhibition of CYP2D6 by haloperidol metabolites: stereoselective inhibition by reduced haloperidol. Br J Clin Pharmacol 51:45-52

Shulman Y, Tibbo PG (2005) Neuroactive steroids in schizophrenia. Can J Psychiatr 50:695-703

Simpson ER, Clyne C, Rubin G, Boon WC, Robertson K, Britt K, Speed C, Jones M (2002) Aromatase-a brief overview. Annu Rev Physiol 64:93-127

Spina E, Scordo MG, D’Arrigo C (2003) Metabolic drug interactions with new psychotropic agents. Fund Clin Pharmacol 17:517-553

Stoffel-Wagner B (2001) Neurosteroid metabolism in the human brain. Eur J Endocrinol 145:669-679

Stracina T, Slaninova I, Polanska H, Axmanova M, Olejnickova V, Konecny P, Masarik M, Krizanova O, Novakova M (2015) Longterm haloperidol treatment prolongs QT interval and increases expression of sigma 1 and IP3 receptors in Guinea pig hearts. Tohoku J Exp Med 236:199-207

Ulhaq ZS, Kishida M (2018) Brain aromatase modulates serotonergic neuron by regulating serotonin levels in zebrafish embryos and larvae. Front Endocrinol (Lausanne) 9:230

Vierk R, Glassmeier G, Zhou L, Brandt N, Fester L, Dudzinski D, Wilkars W, Bender RA, Lewerenz M, Gloger S, Graser L, Schwarz J, Rune GM (2012) Aromatase inhibition abolishes LTP generation in female but not in male mice. J Neurosci 32:116-126

Xing L, Esau C, Trudeau VL (2016) Direct regulation of aromatase B expression by $17 \beta$-estradiol and dopamine D1 receptor agonist in adult radial glial cells. Front Neurosci 12:504

Publisher's Note Springer Nature remains neutral with regard to jurisdictional claims in published maps and institutional affiliations. 